\title{
Prevención en la formación de atelectasias durante la inducción anestésica en pediatría. Estudio randomizado
}

Gerez SA., Venturin N., Rudzik N., Santanera B., Portela F., Viotti F., Tusman G., Acosta MC.

Introducción: En pacientes adultos la inducción anestésica con CPAP ha demostrado disminuir la incidencia de atelectasias y se asocia con una mejor oxigenación. Nuestro estudio fue diseñado para evaluar el efecto de $5 \mathrm{cmH} 2 \mathrm{O}$ de CPAP durante la inducción anestésica en pacientes pediátricos, para prevenir la formación de atelectasias inducidas por anestesia general. Presentamos datos preliminares de este estudio.

Método: Cuarenta y dos niños de 6 meses a 7 años, ASA I-II, programados para cirugía bajo anestesia general con ventilación mecánica recibieron un seteo de ventilación protectiva controlada por volumen con un volumen tidal 6 $\mathrm{ml} / \mathrm{kg}$, PEEP $5 \mathrm{cmH} 2 \mathrm{O}$, relación I:E 1:1,5, FiO2 40\%, utilizando un Aespire 7900 (Datex-Ohmeda, GE Healthcare, Helsinki, Finland). Los pacientes fueron randomizados en dos grupos: 1) Grupo Control (grupo-C), $n=21$, recibieron inducción anestésica a través de un circuito circular sin CPAP (presión positiva continua en la via aérea); 2) Grupo CPAP, $\mathrm{n}=21$, los pacientes recibieron inducción con circuito circular utilizando CPAP. Durante el intra-operatorio aquellos pacientes del grupo CPAP que presentaron atelectasias post-inducción anestésica, evidenciadas por ultrasonido pulmonar o test del aire positivo $(\mathrm{SpO} 2 \leq 96 \%)$ recibieron maniobra de reclutamiento con un seteo posterior de PEEP de 8-9 cmH2O.

Un score de aireación pulmonar fue obtenido utilizando ecógrafo portátil Esaote (MyLab Gamma, Genova, Italy) con sonda lineal HF 6-12 MHz post-inducción (T1) y al finalizar la cirugía (T2).

Resultados: Enrolamos 42 pacientes ASA I, las características demográficas y duración de la cirugía fueron similares en ambos grupos estudiados (Tabla 1).

El score de aireación fue obtenido en ambos grupos en T1 y T2 (Figura 1) Post-inducción anestésica (T1) el grupo CPAP obtuvo un score de aireación significativamente menor al grupo-C, $(3,48 \pm 8,76 ; \mathrm{p}<0,001$, respectivamente). En T2 el score de aireación disminuyo en el grupo CPAP $(3,48$ vs 1,76) manteniendo una diferencia significativa con el grupo-C $(1,76$ vs 9,$62 ; \mathrm{p}<0,001)$.

Conclusiones: Las atelectasias inducidas por anestesia general observadas frecuentemente en pacientes pediátricos fueron prevenidas más eficazmente en los pacientes que recibieron una inducción con CPAP. Esta estrategia aporta oxígeno y anestésico inhalatorio a una presión positiva de $5 \mathrm{cmH} 20$, lo cual mantendría abiertos los alveolos y mejoraría la oxigenación al reducir el shunt a través de áreas atelectásicas.

https://doi.org/10.25237/congresoclasa2019.85 